\title{
Prevalence of Extended Spectrum Beta Lactamases (ESBL) and Metallo Beta Lactamases (MBL) Mediated Resistance inGram Negative Bacterial Pathogens
}

\author{
Pramila Pathak ${ }^{1}$, Nandalal Jaishi ${ }^{2}$, Binod Kumar Yadav ${ }^{2}$, Pradeep Kumar Shah ${ }^{1}$ \\ ${ }^{1}$ Department of Microbiology, Tri-Chandra Multiple Campus, Ghantaghar, Kathmandu, \\ ${ }^{2}$ Department of Microbiology, Shahid Gangalal National Heart Center, Bansbari, Kathmandu, Nepal \\ * Corresponding author: Pradeep Kumar Shah, Department of Microbiology, Tri-Chandra Multiple \\ College, Ghantaghar, Kathmandu, Email: pkshah210@gmail.com
}

\section{ABSTRACT}

Objectives: This study was conducted to determine the prevalence of multi-drug resistance (MDR) along with Extended Spectrum $\beta$-lactamase (ESBL) and Metallo $\beta$-lactamase (MBL) producing gram negative bacterial isolates among the patients attending Shahid Gangalal National Heart Centre, Kathmandu, Nepal.

Methods: This cross-sectional study was carried out from June to December; 2016. Altogether 977 clinical specimens were processed for analysis of bacteriological profile and the isolates were identified by culture, morphological and biochemical tests. Antibiotic susceptibility testing of the isolates was performed by Kirby Bauer disc diffusion methods following Clinical and Laboratories Standard Institute guideline and the isolates were tested for ESBL and MBL by combined disk method.

Results: out of 977 clinical specimens, 254 (25.99\%) were found to be gram negative bacterial isolates, among them Klebsiella pneumoniae $83(32.67 \%)$ was the most predominant organism followed by $E$. coli 51 (20.07\%), Pseudomonas aeruginosa 36 (14.17\%), K. oxytoca 32 (12.59\%), Proteus mirabilis $13(5.11 \%)$ and P. vulgaris 13 (5.11\%), Acinetobacter spp. 11 (4.33\%), Citrobacter spp. 10 (3.93\%) and Enterobacter spp. 5 (1.96\%) respectively. 83 (32.67\%) isolates were found to be MDR, 38(14.96\%) were positive for ESBL while 19 (7.48\%) were MBL producer.

Conclusion: The determent drug resistance among ESBL and MBL producers, reflect the extensive use of antibiotics possessing difficulties in therapeutic potions in hospital setting which might be overcome by proper microbiological analysis of pathogenic isolates and judicious use of antibiotics for emergence of resistance strains.

Key words: Clinical Specimen, Gram negative bacteria, MDR, ESBL, MBL

\section{INTRODUCTION}

Antibiotics have been critical in the fight against infections caused by bacteria and other microbes. The most common and important mechanism of resistance in Gram-negative bacteria is production of $\beta$-lactamases. Antibiotic resistance is particularly rising because of inappropriate use of antibiotics in human medicine (Tiersma 2013). Multidrug resistance has been increasing among Gram negative bacteria (Bush 2010). Beta- Lactamases are enzymes produced by some bacteria that hydrolyze the amide bond of the fourmembered characteristic $\beta$-lactam ring (Peshattiwar and Peerapur 2011) of $\beta$-lactam antibiotics (penicillin, cephalosporin, monobactams, and carbapenems) (Noyal et al. 2009), result in an inactive product when the ring is broken (Simoens et al. 2006). In recent years, there has been an increase in incidence and prevalence of ESBL producing microbial diseases (Thokar et al. 2010). More than 200 types of extended spectrum $\beta$ lactamases (ESBLs) have been found worldwide, most belonging to the Enterobacteriaceae family (Yazdi et al. 2012). MBLs have been globally isolated from various bacteria and more than 80 types of MBLs have been identified worldwide, with over $75 \%$ occurring 
as plasmid encoded enzymes (Bush and Jacoby 2010). Early detection of MBL and ESBL producing organisms is crucial to establish appropriate antimicrobial therapy and to prevent their interhospital and intrahospital dissemination (Pandey et al. 2011). Thus, the present study was conducted with an objective to find out the presence of ESBL and MBL producing gram negative bacterial isolates and multidrug resistant strains to formulate effective antibiotic strategy on the basis of the local epidemiological data to control infection and to prevent the spread of these strains.

\section{MATERIALS AND METHODS}

A total of 977 clinical specimens including blood, urine, sputum, pus, ET tip secretion, CVP tip, suction tube, Foley's tip, pericardial fluid, body fluid (peritoneal fluid), throat swab, pleural fluid, wound swab, mitral valve vegetation, mediastinal drain culture, aortic valve, tracheal aspirate wascollected in a clean, leak-proof sterile container during June, 2016 to December, 2016 from the cardiac patients attending Shahid Gangalal National Heart Center, Bansbari, Kathmandu, Nepal.

The specimens were subjected for routine culture and susceptibility testing in the microbiology department. For blood sample 3-5 $\mathrm{ml}$ of blood was inoculated into brain-heart infusion broth and incubated at $37^{\circ} \mathrm{C}$ and sub-cultures were made on blood agar (BA) and McConkey agar (MA) after 24, 48 and 72 hours. BHI broth was incubated aerobically for upto 7 days at 37 ${ }^{\circ} \mathrm{C}$ whereas others samples were inoculated onto BA and MA plates. The plates were incubated at $37{ }^{\circ} \mathrm{C}$ for 24 hrs. The significant bacterial isolates were identified on the basis of morphology, gram staining \& various biochemical tests. Antibiotic susceptibility testing of the isolates was performed by Kirby Bauer disc diffusion method following Clinical and Laboratories Standard Institute (CLSI) guideline and they were tested for ESBL and MBL by combined disk method. K. pneumoniae ATCC 700603 positive controls for ESBL and P. aeruginosa PA 105663 positive control for MBL were used. Statistical analysis was done by using SPSS version 16. Frequency and percentages were calculated and Chi-square test was done whenever applicable with $\mathrm{P}<0.05$ regarded as significant.

\section{RESULTS}

Among the total 977 clinical specimens for culture,295 $(30.19 \%)$ showed significant bacterial growth of which $254(25.99 \%)$ were gram negative bacteria while 41 (4.19\%) were gram positive bacteria. Out of 254 gram negative bacterial isolates, $123(48.42 \%)$ were from the samples of female and 131 (51.57\%) were from male patients. Likewise, $52(5.32 \%)$ were from outpatients and remaining 202 (20.67\%) were from inpatients. However, there was significant difference in bacterial growth between the samples of outpatients and inpatients $(\mathrm{P}$ value $=27.16)$. The age of the patients ranged from 49 days to 87 years. The highest percentage of bacterial growth 7 (18.50\%) was obtained in samples of age group <10yrs, followed by $44(17.32 \%)$ in age group 51-60yrs, whereas least $6(2.36 \%)$ was from age group 81-90 yrs. Highest percentage of growth was found to be in samples of male $11(4.33 \%)$ in age group 51-60 yrs. whereas for Female, highest \% of growth 14 $(5.51 \%)$ was in age group $21-30$ yrs.

Table 1: Distribution of clinical specimens

\begin{tabular}{|c|c|c|c|c|c|c|c|c|c|}
\hline \multirow{2}{*}{ Clinical samples } & \multicolumn{2}{|c|}{ Gender } & \multicolumn{2}{|c|}{ In patients } & \multicolumn{2}{|c|}{ Out patients } & \multicolumn{2}{|c|}{ Significant growth } & \multirow{2}{*}{ Total No. } \\
\hline & Female & Male & No. & $\%$ & No. & $\%$ & No. & $\%$ & \\
\hline Blood & 96 & 166 & 144 & 54.96 & 118 & 45.03 & 22 & 8.39 & 262 \\
\hline Body Fluid & 1 & 8 & 7 & 77.78 & 2 & 22.22 & 2 & 22.22 & 9 \\
\hline CVP tip & 8 & 19 & 27 & 100 & 0 & 0 & 10 & 37.03 & 27 \\
\hline ET Tip & 26 & 55 & 62 & 76.54 & 19 & 23.45 & 40 & 49.38 & 81 \\
\hline Foley Tip & 3 & 9 & 11 & 91.66 & 1 & 8.33 & 8 & 66.67 & 12 \\
\hline Others & 19 & 35 & 43 & 79.62 & 11 & 20.38 & 11 & 20.37 & 54 \\
\hline Pericardial fluid & 15 & 22 & 29 & 78.37 & 8 & 21.62 & 7 & 18.91 & 37 \\
\hline Pus & 32 & 15 & 35 & 74.46 & 12 & 25.53 & 13 & 27.65 & 47 \\
\hline Sputum & 44 & 40 & 48 & 57.14 & 36 & 42.85 & 37 & 44.04 & 84 \\
\hline Suction Tip & 6 & 10 & 14 & 87.5 & 2 & 12.5 & 10 & 62.5 & 16 \\
\hline Throat Swab & 5 & 6 & 8 & 72.73 & 3 & 27.27 & 2 & 18.18 & 11 \\
\hline Urine & 189 & 138 & 211 & 64.52 & 116 & 35.47 & 92 & 28.13 & 327 \\
\hline Total & $\begin{array}{c}447 \\
(45.75)\end{array}$ & $\begin{array}{c}530 \\
(54.24)\end{array}$ & $\begin{array}{c}647 \\
(66.22)\end{array}$ & & $\begin{array}{c}330 \\
(33.77)\end{array}$ & & $\begin{array}{c}254 \\
(25.99)\end{array}$ & & 977 \\
\hline
\end{tabular}


In this study, out of 7 different bacterial genera isolated, Klebsiella pneumoniae 83 (32.67\%) was being the most predominant whereas Enterobacter spp. was being least 5 (1.96\%). Pseudomonas aeruginosa was most predominant from indoor patients 34 (94.44\%) while Citrobacter spp. was being least 4 (40\%). Similarly, from outpatient, Citrobacter spp. was most predominant 6 (60\%) whereas P. aeruginosa showed least growth 2 (5.56\%).

Table 2: distribution pattern of gram negative bacterial isolates from various clinical samples

\begin{tabular}{|c|c|c|c|c|c|c|c|c|c|c|c|}
\hline \multirow{2}{*}{ Clinical samples } & \multirow{2}{*}{ 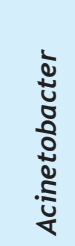 } & \multirow{2}{*}{ 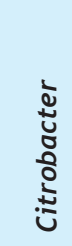 } & \multirow{2}{*}{ 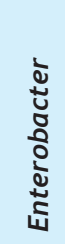 } & \multirow[b]{2}{*}{ ن } & \multicolumn{2}{|c|}{ Klebsiella } & \multicolumn{2}{|c|}{ Proteus } & \multirow{2}{*}{ 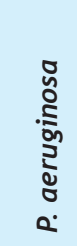 } & \multicolumn{2}{|l|}{ Total } \\
\hline & & & & & \begin{tabular}{l}
0 \\
o \\
\multirow{2}{x}{} \\
ô
\end{tabular} & $\begin{array}{l}\text { ఏ } \\
\text { క } \\
\text { ¿ }\end{array}$ & 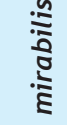 & $\begin{array}{l}\frac{n}{5} \\
\frac{0}{3} \\
\frac{3}{3}\end{array}$ & & No. & $\%$ \\
\hline Blood & 0 & 0 & 3 & 5 & 3 & 6 & 0 & 1 & 4 & 22 & 8.66 \\
\hline Body fluid & 0 & 0 & 0 & 0 & 1 & 0 & 0 & 0 & 1 & 2 & 0.78 \\
\hline CVP tip & 1 & 0 & 1 & 2 & 1 & 4 & 0 & 0 & 1 & 10 & 3.93 \\
\hline ET tips & 2 & 1 & 0 & 8 & 3 & 11 & 2 & 1 & 12 & 40 & 15.74 \\
\hline Foley's tip & 0 & 0 & 0 & 1 & 2 & 2 & 0 & 0 & 3 & 8 & 3.14 \\
\hline Others & 0 & 1 & 0 & 1 & 2 & 4 & 2 & 0 & 1 & 11 & 4.33 \\
\hline Pericardial fluid & 1 & 0 & 0 & 1 & 0 & 1 & 0 & 0 & 4 & 7 & 2.75 \\
\hline Pus & 0 & 1 & 0 & 1 & 5 & 4 & 1 & 1 & 0 & 13 & 5.11 \\
\hline Sputum & 0 & 0 & 0 & 2 & 1 & 24 & 2 & 1 & 7 & 37 & 14.56 \\
\hline Suction tip & 2 & 1 & 0 & 1 & 0 & 2 & 3 & 0 & 1 & 10 & 3.93 \\
\hline Throat swab & 0 & 0 & 0 & 1 & 0 & 1 & 0 & 0 & 0 & 2 & 0.78 \\
\hline Urine & 5 & 6 & 1 & 28 & 14 & 24 & 3 & 9 & 2 & 92 & 36.22 \\
\hline \multirow{2}{*}{ Total } & 11 & 10 & 5 & 51 & 32 & 83 & 13 & 13 & 36 & 254 & 100 \\
\hline & 4.3 & 3.9 & 1.9 & 20.1 & 12.6 & 32.7 & 5.1 & 5.1 & 14.2 & & 100 \\
\hline
\end{tabular}

The most effective drug for gram negative pathogenic bacteria was nitrofurantoin followed by Gentamicin, ciprofloxacin and cotrimoxazole. The highest MDR strain was found to be Acinetobacter spp. 6 (54.54\%) whereas Enterobacter spp. (0\%) did not show any MDR pattern.

Table 3: Antibiotic resistance pattern of gram negative bacterial isolates

\begin{tabular}{|c|c|c|c|c|c|c|c|}
\hline \multirow{2}{*}{$\begin{array}{l}\text { Bacterial isolates / } \\
\text { total no. }\end{array}$} & \multicolumn{7}{|c|}{ Antibiotics (\% Resistance) } \\
\hline & Amp & Caz & Cipro & Cotri & Genta & Nali & Nitro \\
\hline Acinetobacter (11) & $7(63.63)$ & $8(72.73)$ & $2(18.18)$ & $4(36.36)$ & $3(27.27)$ & $7(63.63)$ & $0(0)$ \\
\hline Citrobacter (10) & $7(70.0)$ & $6(60.0)$ & $3(30.0)$ & $4(40.0)$ & $3(30.0)$ & $6(60.0)$ & $0(0)$ \\
\hline Enterobacter (5) & $4(80.0)$ & $1(20.0)$ & $2(40.0)$ & $0(0)$ & $0(0)$ & $3(60.0)$ & $0(0)$ \\
\hline E. coli $(\mathrm{n}=51)$ & $43(84.31)$ & $36(70.58)$ & $21(41.17)$ & $21(41.17)$ & $17(17.64)$ & $31(60.78)$ & $4(14.28)$ \\
\hline K. oxytoca (32) & $23(71.87)$ & $14(63.85)$ & $11(34.37)$ & $10(31.25)$ & $9(28.12)$ & $27(84.37)$ & $0(0)$ \\
\hline K. pneumonia (83) & $68(79.06)$ & $53(63.85)$ & $17(20.48)$ & $30(36.14)$ & $13(15.66)$ & $48(57.83)$ & $2(8.33)$ \\
\hline P. mirabilis (13) & $5(38.46)$ & $6(46.15)$ & $2(15.38)$ & $4(30.76)$ & $2(15.38)$ & $4(30.76)$ & $0(0)$ \\
\hline P. vulgaris (13) & $4(30.76)$ & $8(61.53)$ & $5(38.46)$ & $5(38.46)$ & $8(61.53)$ & $8(61.53)$ & $1(11.11)$ \\
\hline P. aeruginosa (36) & $29(80.56)$ & $26(72.22)$ & $14(38.89)$ & $9(25.0)$ & $10(27.78)$ & $27(75.0)$ & $0(0)$ \\
\hline Total (254) & $190(74.48)$ & $158(62.2)$ & $77(30.31)$ & $87(34.25)$ & 65 (25.59) & $161(63.38)$ & $7(2.75)$ \\
\hline
\end{tabular}


Pathak et al. 2017; TUJM 4(1): 49-54

Table 4: Distribution of MDR, ESBL and MBL producer among gram negative bacterial isolates

\begin{tabular}{lcccc}
\hline Bacterial isolates & No. & MDR strains No. (\%) & ESBL producer No. (\%) & MBL producers No. (\%) \\
\hline Acinetobacter & 11 & $6(54.54 \%)$ & 0 & $1(9.09)$ \\
Citrobacter & 10 & $3(30 \%)$ & $2(20 \%)$ & 0 \\
Enterobacter & 5 & 0 & 0 & 0 \\
E. coli & 51 & $19(37.25 \%)$ & $6(54.54 \%)$ & $2(3.92 \%)$ \\
K. oxytoca & 32 & $7(21.87 \%)$ & $5(15.62 \%)$ & 0 \\
K. pneumonia & 83 & $29(34.93 \%)$ & $13(15.66 \%)$ & $7(8.43 \%)$ \\
P. mirabilis & 13 & $2(15.38 \%)$ & $1(7.69 \%)$ & 0 \\
P. vulgaris & 13 & $1(7.69 \%)$ & $1(7.69 \%)$ & 0 \\
P. aeruginosa & 36 & $16(44.44 \%)$ & $4(11.11 \%)$ & $9(25 \%)$ \\
\hline Total & 254 & $83(32.67 \%)$ & $38(14.96 \%)$ & $19(7.48 \%)$ \\
\hline
\end{tabular}

The highest no. of ESBL producer was isolated from ET Tip 10 (25\%) and least from pus 1 (7.69\%). Similarly, for MBL producers, it was throat swab 1 (50\%) and least from urine 3 (3.26\%). The Antibiotic susceptibility pattern of ESBL producers revealed that, they were $100 \%$ resistant against ampicillin and ceftazidime but sensitive towards nitrofurantoin $(100 \%)$ followed by imipenem $(81.58 \%)$, amikacin $(73.7 \%)$, ofloxacin $(63.2 \%)$ gentamicin $(57.9 \%)$ and cotrimoxazole $(50 \%)$. MBL producers showed resistance towards most of the drug used and were sensitive towards polymyxin.

\section{DISCUSSION}

This study was aimed to examine the status of MDR among different gram negative bacterial pathogens and underlying production of ESBLs and MBLs. The highest percentage of sample obtained was urine $(33.46 \%)$ whereas body fluid i.e. peritoneal fluid $(0.92 \%)$ was found in a least percentage which was correlated with the study done where higher percent of sample collected was urine (Sherchan et al. 2016). The frequency of growth pattern among individual specimens were highest from Foley tips (66.67\%) similar to the study done by Sherchan et al. 2016 which shows $61.11 \%$ from catheter, whereas least growth obtained from blood sample $(8.39 \%)$, a similar study conducted in western Nepal in 2007 showed the isolation rate from blood was $10.28 \%$ (Easow et al. 2010) and a study by (Vanitha et al. 2012) also showed $8.39 \%$.This least growth from blood sample might be due to patient may have already taken antibiotics or he or she may not have systemic infection so far. and high \% of urinary catheter use is a risk factor for inoculation of bacteria into bladder.No significant difference in growth number between male and female patients revealed that both of them have equal chance of having heart diseases. Enterobacter spp. were least isolates to cause infection predominated from blood sample whereas E. coli (20.07\%) was second predominant organism from urine after Klebsiella pneumonia (32.67\%) from urine and sputum sample contrast to a study (Chander and Shrestha 2013), reported low prevalence of $K$. pneumoniae from urine sample. More isolation rate of $K$. pneumoniae due to contamination of invasive devices, weakened immune system, nosocomial infection. Whereas E. coli was predominant in urine sample, resembled the study done by various others workers viz: (Shrestha et al. 2012), (Mishra et al. 2012) and (Manandhar et al. 2006) in Nepal. This high incidence of the E. coli is a commensal of the bowl and infection due to poor hygiene and anatomy proximity to the genito-urinary area. Highest percentage of resistance towards first line antibiotic ampicillin, Nalidixic acid, and ceftazidime with considerable resistivity to ampicillin $(74.48 \%)$ which was found to be congruous with the study done by (Bhatt et al. 2012).

In this study, no MDR strains were observed in Enterobacter spp. while highest number of MDR was found in Acinetobacter spp. (54.54\%) whereas lowest from P. vulgaris (7.69\%). These results were less than outcomes of previous studies (Karn et al. 2016) which showed 42.91\% were MDR, and Acinetobacter spp. account for $60 \%$. This is due to drugs are easily available without doctor's prescription from pharmacy and in developing countries like Nepal self-medication is a common practice. ESBLs were predominantly present among $E$. coli $(23.52 \%)$ followed by Citrobacter spp. similar to the study done by Pokhrel et al. in which $16.0 \%$ isolates were found to be ESBL producing with E. coli being the predominant one (11.60\%) (Pokharel et al. 2006) and also study done by (Ahmed et al. 2014) in which $18.95 \%$ were 
ESBL producers. $3^{\text {rd }}$ generation Cephalosporins were combined with $\beta$-lactamases inhibitor Clavulanic acid (i.e. CTX30 + Clav10 and CAZ 30+ Clav10), structural analog of $\beta$-lactamase and antibiotics inhibits the action of $\beta$-lactamases and antibiotic can act on the cell wall of the bacteria, result confirmed by at least or more than $5 \mathrm{~mm}$ increase in zone of inhibition than Cephalosporins alone ( Rawat and Nair 2010). K. pneumoniae responsible for ESBL and MBL production resulting a potential threat to hospitalized patients by limiting therapeutic option (Bora et al. 2014). ESBLs are mostly produced by E. coli and Klebsiella spp. but may also occur in other Gramnegative bacteria including Citrobacter spp., Morganella spp., Proteus spp., Pseudomonas spp., Salmonella spp. Serratia spp. and Shigella spp. (Akujobi and Ewuru 2010). A (Dalela 2012) study showed that imipenem is the most active drug for the treatment of infections which are caused by ESBL producers, followed by Amikacin which is similar to our finding. $7.48 \%$ isolates were found to be MBL producers which is higher than Mishra et al. 2012 (1.3\%) and lesser than Haider et al. 2014 (17.93\%) highest MBL producer being Pseudomonas aeruginosa (Mishra et al. 2012) and (Haider et al. 2014). And similar to previous study conducted at SGNHC which showed $8.4 \%$ were MBL producers (Chaudhary et al. 2016). Our findings of P. aeruginosa (25\%) as the most common MBLs producer followed by Acinetobacter spp., K. pneumoniae and E. coli being least MBL producer which is exactly similar with Kamble 2015 (Kamble 2015) in which P. aeruginosa (23.62\%), higher than study done in India by Agrawal 2008 which showed only 8.05\% (Agrawal et al. 2008). It is a nosocomial pathogen of particular clinical concern not only because of its extraordinary resistance mechanisms but also for its formidable ability to adept very well to the hospital environment.

\section{CONCLUSION}

The prevalence of Gram negative bacteria based upon observed in 977 clinical samples was found to be $25.99 \%$ and an antibiogram, revealed the presence of ESBL and MBL enzyme in multidrug resistant gramnegative isolates which reflects the extensive use of antibiotics for the treatment in hospitals. Therefore, proper identification of isolates using microbiological tools should be undertaken. These types of study could help to estimate and to employ effective antimicrobial strategy so that the emergence of resistant strains could be reduced.

\section{ACKNOWLEDGEMENTS}

We would like to thank all the patients whose samples were used in the study, all the staff of Shahid Gangalal National Heart Centre, all the faculties and Staffs of Department of Microbiology, Tri-Chandra Multiple Campus.

\section{REFERENCES}

Agrawal P, Ghosh AN, Kumar S, Basu B and Kapila K (2008) Prevalence of extended-spectrum betalactamases among Escherichia coli and Klebsiella pneumoniae isolates in a tertiary care hospital. Indian J Pathol Microbiol 51(1): 139-42.

Ahmed SM, Rajeevan S, Jasmin P T and Shakir V A (2014) Detection of ESBL among the gram negative uropathogens and their antibiotic resistance pattern in a rural medical college hospital North Kerala, India. Int J Curr Microbiol App Sci 3(2): 561-567.

Akujobi CN and Ewuru CP (2010) Detection of extended spectrum beta-lactamases in gram negative bacilli from clinical specimens in a teaching hospital in South eastern Nigeria. Niger Med J 51(4): 141-146.

Bhatt C P, Shrestha B, Khadka S, Swar S, Shah B and Pun K (2012) Etiology of Urinary tract infection and drug resistance cases of uropathogens. Journal of Kathmandu Medical College 1(2): 114-120.

Bora A, Sanjana R, Jha BK, Mahaseth SN and Pokhrel $\mathrm{K}$ (2014) Incidence of metallo-beta-lactamase producing clinical isolates of Escherichia coli and Klebsiella pneumoniae in central Nepal. BMC Research Notes 7: 557.

Bush K (2010) Bench-to-bedside review: The role of beta-lactamases in antibiotic-resistant Gramnegative infections. Critical Care 14(3): 224.

Bush K and Jacoby GA (2010) Updated functional classification of $\beta$-lactamases. Antimicrob Agents Chemother 54: 969-976.

Chander A and Shrestha CD (2013) Prevalence of extended spectrum beta lactamase producing Escherichia coli and Klebsiella pneumoniae urinary isolates in a tertiary care hospital in Kathmandu, Nepal. BMC Research Notes 6: 487.

Chaudhary AK, Bhandari D, Amatya J, Chaudhary P and Acharya B (2016) Metallo-Beta-Lactamase Producing Gram-Negative Bacteria among 
Patients Visiting Shahid Gangalal National Heart Centre. Austin J Microbiol 2(1):1010.

Dalela G (2012) Prevalence of extended spectrum beta lactamase (ESBL) producers among Gram negative bacilli from various clinical isolates in a tertiary care hospital at Jhalawar, Rajasthan, India. Journal of Clinical and Diagnostic Research 6(2): 182-187.

Easow MJ, Joseph MN, Dhungel AB, Chapagain B and Shivananda PG (2010) Blood steams infections among fabrile patient attending a teaching hospital in western regions, Nepal. AMJ 3: 633-37.

Haider M, Riziv M, Fatima N, Shukla I and Malik A (2014) Necessity of detection of extended spectrum betalactamase, AmpC and metallo-beta-lactamases in Gram-negative bacteria isolated from clinical specimens. Muller J Med Sci Res 5(1): 23-8.

Kamble DS (2015) Phenotypic detection of ESBL and MBL in Gram negative bacilli isolated from clinical specimens. Int J Med Res Rev 3(8): 866-870.

Karn S, Pant ND, Neupane S, Khatiwada S, Basnyat S and Shrestha B (2016) Prevalence of carbapenem resistant bacterial strains isolated from different clinical samples: study from a tertiary care hospital in Kathmandu, Nepal. Journal of Biomedical Sciences 3(1): 11-15.

Manandhar T, Koirala J, Pokhrel BM and Ghimire P (2006) Status of extended spectrum beta lactamase producing. Journal of Institute of Medicine 28(2): 2429.

Mishra SK, Acharya J, Kattel HP, Koirala J, Rijal BP and Pokhrel BM (2012) Metallo-beta-lactamase producing gram-negative bacterial isolates. J Nepal Health Res Counc 10(22): 208-13.

Noyal MJC, Menezes GA, Harish BN, Sujatha S and Parija SC (2009) Simple screening tests for detection of carbapenemases in clinical isolates of nonfermentative Gram-negative bacteria. Indian J Med Res 129(6): 707-12

Pandey N, Prajapati SB, Mehta SJ, Kikani KM and Joshi PJ (2011) Evaluation of various methods for detection of metallo- $\beta$-lactamase production in gram negative bacilli. Int J Biol Med Res 2(3): 775777.

Peshattiwar PD and Peerapur BV (2011) ESBL and MBL
Mediated Resistance in Pseudomonas aeruginosa: An Emerging threat to clinical therapeutics. Journal of Clinical and Diagnostic Research 5(8): 1552 - 1554

Pokharel BM, Koirala J, Mishra SK, Dahal RK, Khadga P and Tuladhar NR (2006) Multidrug-resistant and extended-spectrum beta-lactamase producing strain causing lower respiratory tract and urinary tract infections. Journal of Institute of Medicine 28(3): 19-27.

Rawat D and Nair D (2010) Extended-spectrum $\beta$-lactamases in Gram negative bacteria. J Glob Infect Dis 2(3): 263-274.

Sherchan S, Shrestha D, Gurung K, Sherchand SP, Manandhar S, Shrestha B (2016) Prevalence of multidrug resistant extended-spectrum $\beta$-lactamaseproducing. EC Microbiology 4(2): 676-698.

Shrestha B, Gurubacharya RL, Maharjan B and Shrestha S (2012) Multi drug resistant pathogens causing urinary tract infections in children at Kathmandu Model Hospital. J Nepal Paediatric Soc 32(3): 233238.

Simoens S, De Corte N and Laekeman G (2006) Clinical practice and costs of treating catheter-related infections with teicoplanin or vancomycin. Pharmacy Practice 4(2): 68-73.

Thokar MA, Fomda BA, Maroof P, Ahmed K, Bashir D and Bashir G (2010) Proliferation of extended spectrum $\beta$-lactamase (ESBL) producing Gram negative bacteria, diagnostic inputs and impact on selection of antimicrobial therapy. Physician Academy 4(3): 25-31.

Tiersma Y (2013) $\beta$-Lactamase-producing bacteria How can I resist you?, M.Sc. dissertation submitted to department of Biology Science Utrecht University.

Vanitha RN, Kannan G, Venkata NM, Vishwakanth D, Nagesh VD and Yogitha M (2012) A retrospective study on blood stream infections and antibiotic susceptibility patterns in a tertiary care teaching hospital. Int J Pharm Pharm Sci 4: 543-48.

Yazdi M, Nazemi A, Mirinargasi M, Jafarpour M and Sharifi SH (2012) Genotypic versus Phenotypic methods to detect Extended-Spectrum Betalactamases (ESBLs) in Uropathogenic Escherichia coli. Annuals of Biological Research 3(5): 2454-2458. 